Research Article

\title{
Compensation Method for Inclination Errors in Measurement Results of Tooth Surface of Spiral Bevel Gear
}

\author{
Yongsheng Liu $\mathbb{D},,^{1,2}$ Suping Fang $\mathbb{D},^{3}$ Yixin Chen $\mathbb{D},{ }^{1}$ and Jianye Zhang $\mathbb{D}^{1}$ \\ ${ }^{1}$ Key Laboratory of Road Construction Technology and Equipment, MOE, Chang'an University, Xi'an 710064, Shaanxi, China \\ ${ }^{2}$ Key Laboratory of Advanced Manufacture Technology for Automobile Parts, MOE, Chongqing University of Technology, \\ Chongqing 400054, China \\ ${ }^{3}$ State Key Laboratory for Manufacturing System Engineering, School of Mechanical Engineering, Xi'an Jiaotong University, \\ Xi'an 710049, Shaanxi, China
}

Correspondence should be addressed to Yongsheng Liu; lysh@chd.edu.cn

Received 20 October 2020; Revised 13 March 2021; Accepted 17 March 2021; Published 31 March 2021

Academic Editor: Bekir Sahin

Copyright $(2021$ Yongsheng Liu et al. This is an open access article distributed under the Creative Commons Attribution License, which permits unrestricted use, distribution, and reproduction in any medium, provided the original work is properly cited.

The manufacturing error of spiral bevel gear tooth surface has a great influence on transmission efficiency and gear life. The error of the gear tooth surface needs to be measured accurately and fed back to the machine tool to adjust the parameters. When measuring the spiral bevel gear using a gear measuring machine, combined with the measurement theory of the tooth flank of spiral bevel gear, this paper proposed a method to compensate the inclination error in the measurement result precisely. Based on the iterative search method, a precision matching method for the theoretical and the measured tooth surface of the spiral bevel gear was designed to calculate the compensation results. The experimental results show that the inclination errors included in tooth surface measurement results reduced from more than $3 \mu \mathrm{m}$ to less than $0.5 \mu \mathrm{m}$, and more than $70 \%$ of the errors are compensated by the proposed method. The accuracy of the measurement results improved significantly after compensation, and furthermore, it can provide a more accurate basis for the adjustment of machine tool parameters in the manufacturing process.

\section{Introduction}

Spiral bevel gear is widely used in the field of mechanical transmissions, such as automobile, aviation, wind turbines, and so on. When manufacturing the gear by machine tools, the manufacturing error affects the accuracy of the gear tooth surface and then directly affects the performance of gear transmission efficiency, noise, lifetime, and reliability [1-4]. In the closed-loop manufacturing system, in order to feedback and adjust the machine tool parameters, the gear tooth surface requires to improve its measuring accuracy. At present, the coordinate measurement method is one of the most widely used methods to measure the tooth surface error of the spiral bevel gear [5-7].

When measuring the tooth surface of spiral bevel gear by gear measuring machine (GMM), the manufacturing and assembly error of the gear is inevitable. The inclination error caused by the nonparallel between the gear axis and the vertical rotation axis of GMM will affect the measurement results of spiral bevel gear $[8,9]$. Therefore, to improve the measurement accuracy of the spiral bevel gear tooth surface, first of all, the measured tooth surface of the gear and its theoretical tooth surface must be accurately matched to eliminate the inclination error in the measurement result of the gear tooth surface [10].

Many works have been done on the measurement error and the compensation method of spiral bevel gear tooth surface. In order to predict the relative errors of alignment between spiral bevel gears, Fuentes et al. proposed a procedure of determination of the relative spatial position of spiral bevel gear supporting shafts during torque transmission [11-13]. The misalignment problem for the spiral bevel and hypoid gears usually exists in the actual manufacturing and transmission, and Ding et al. presented an automatic data-driven operation and optimization to determine the uncertain misalignment [14]. Considering residual tooth flank form error, Shao et al. presented an accurate systematic CMM measurement method to 
prescribe and data-driven control the tooth flank form error and get a flexible compensation of the error [15]. Fu et al. proposed a new online detection method of flatness of spiral bevel gears, and the data of flatness is evaluated by the least square method after error separation [16]. When manufacturing the spiral bevel gears, Shih and You developed an on-machine measurement system on five-axis machines using a quasi-3D probe and verified by comparing the evaluation results with the same gear measured on a dedicated GMM [17]. By using the virtual conjugate reference tooth surface, $\mathrm{Li}$ et al. presented a novel scanning measurement method to measure the tooth flank form of hypoid gears $[18,19]$. Wang et al. established the on-machine measuring and the data processing method for spiral bevel gears, and the method was validated by comparing simulation results with the actual measuring result $[20,21]$. Simon researched the influence of misalignments of the mating members and tooth errors on mesh performances of the spiral bevel gear and found that the misalignments and the tooth spacing error could increase the angular position error of the driven gear [22]. By considering spiral bevel gear geometry, Shunmugam reported a method of determining the normal deviation from the theoretical surface of the bevel gear and then gave the validation of the method [23]. Peng et al. researched the effects of eccentricity error on the gear dynamic responses and proposed a simple method using translational kinematic transmission error modification to reduce the computational time [24]. Using the truncated singular value decomposition and the $L$ curve method, Chen and Yan solved the identification equation of the tooth surface deviation and compared it with the least square method to verify the validation of this method [25]. Xie et al. presented a coordinate measuring method for the variable ratio noncircular bevel gear by coordinate measuring machine [26]. Combined with the theoretical gear and coordinate measuring machine, Cao and Deng provided a method for measuring the errors between the actual surface and the theoretical surface of the bevel gear and then developed the corrective machine setting [27]. Zhou et al. investigated a higher-accuracy fitting method for the form error tooth flank, and the universal machine tool settings are exploited for the identification of the real tooth flank form error [28]. Mo and Zhang gained the corresponding digitized true tooth surface by changing the machining adjustment parameters, which can lay a solid basis for the subsequent finite element analysis of gear contact and transmission error analysis [29]. However, few works have been focused on the measurement error of the spiral bevel gear caused by the inclination error, so it is necessary to research the compensation method for the inclination errors.

Combined with the measurement theory of the tooth flank of spiral bevel gear, this paper proposed a precision matching method for the theoretical tooth surface and the measured tooth surface of the spiral bevel gear, and then compensated the inclination error in the measurement result precisely. The experimental results show that the accuracy of the measurement results improved significantly after compensation.

\section{Establishment of the Measuring Coordinate System}

The design basis of spiral bevel gear is the apex of the pitch cone of the bevel gear, and its design coordinate system is set as $\{O: X, Y, Z\}$. When measuring spiral bevel gear with GMM, the inner end of the gear was fixed upward, and the outer end was fixed downward on the platform, and the measurement basis is the rotation axis of the gear and the outer end surface of the gear.

As shown in Figure 1, the measuring coordinate system of spiral bevel gear $\left\{O_{m}: X_{m}, Y_{m}, Z_{m}\right\}$ is set to coincide with the coordinate system $\{O: X, Y, Z\}$. According to the above coordinate systems, the position of the theoretical gear pitch cone apex in the $Z$-axis direction can be determined by the $Z$-axis coordinate value of the mounting platform and the mounting distance of the gear, and the coordinate relationship between the measured pitch cone apex and the theoretical pitch cone apex can be solved.

\section{Precision Compensation Method for the Measurement Errors of Gear Tooth Surface}

When measuring the tooth surface of spiral bevel gear by GMM, the theoretical data point cloud and the corresponding unit normal vector of the gear tooth surface measuring points should be input GMM first. According to the coordinate value of the theoretical data point cloud, the GMM measures the actual coordinates of the points on the tooth surface and finally obtains the actual measurement error. In order to compensate the inclination error of the rotating axis of the gear, matching the measured tooth surface with the theoretical tooth surface of the gear accurately is the first step.

The spatial relative positions of two curved surfaces can be represented by six relative position parameters of the corresponding points $P$ and $P_{1}:\left\{\Delta x, \Delta y, \Delta z, \Delta \theta_{x}, \Delta \theta_{y}\right.$, $\left.\Delta \theta_{z}\right\}$. When matching the two curved surfaces, the above six parameters should be calculated first, and then one of the two surfaces translated and rotated according to the value of the six parameters to match the other surface in spatial. This paper mainly focuses on the translation deviations $\Delta x$ and $\Delta y$ along the $X$ and $Y$ axis, and the angle deviations $\Delta \theta_{x}$ and $\Delta \theta_{y}$ around the $X$ and $Y$ axis, and finally, find a compensation method for the above four parameters.

Assuming that the point on the measured tooth surface is recorded as point $P_{m}\left(x_{m}, y_{m}, z_{m}\right)$, and the corresponding point on the theoretical tooth surface is named as point $P_{t}$ $\left(x_{t}, y_{t}, z_{t}\right)$. After the surface matching process, the measured tooth surface moves to a new position and the corresponding point of $P_{m}$ is recorded as point $P_{c}\left(x_{c}, y_{c}, z_{c}\right)$. The distance from the point $P_{m}$ to the theoretical tooth surface is $\Delta d$, and the intersection between the normal vector of the theoretical tooth surface that passing through the point $P_{c}$ and the theoretical tooth surface is point $P_{s}\left(x_{s}, y_{s}, z_{s}\right)$. The objective function of the matching method is shown in the following: 


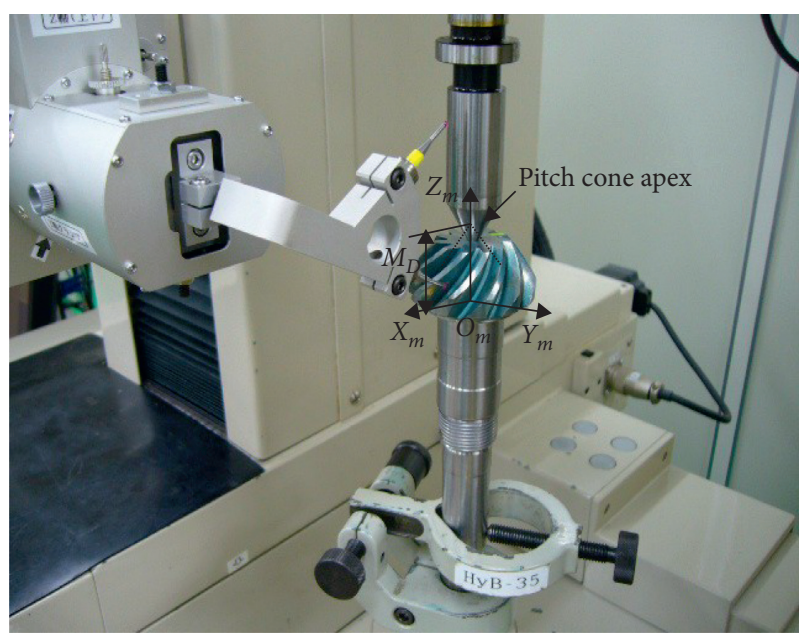

FIGURE 1: Schematic diagram of measuring coordinate system of spiral bevel gear.

$$
\begin{aligned}
\min F\left(\Delta x, \Delta y, \Delta \theta_{x}, \Delta \theta_{y}\right) & =\min \sum_{i=1}^{m} \sum_{j=1}^{n}\left|\left(\vec{P}_{s}-\vec{P}_{m}\right)\right|^{2} \\
& =\min \sum_{i=1}^{m} \sum_{j=1}^{n}\left|\Delta d_{i j}\right|^{2}
\end{aligned}
$$

Due to the inclination error, the position relationship between the measured tooth surface and the theoretical tooth surface is uncertain. Therefore, the position of the point $P_{s}$ corresponding to the point $P_{m}$ needs to be obtained by the search calculation method. As the error of the actual tooth surface is generally small, the position of the point $P_{s}$ is considered nearby the point $P_{t}$, as shown in Figure 2 .

If the corresponding normal vector $\vec{n}_{s}\left(n_{s x}, n_{s y}, n_{s z}\right)$ of point $P_{s}$ passes through the point $P_{m}$, the point $P_{s}$ is the closest point from the point $P_{m}$ to the theoretical tooth surface, and the cosine value of the angle between the vectors $\vec{m}$ and $\overrightarrow{n_{s}}$ is 1 . In order to find the position of the nearest point $P_{s}$ by searching, eight measured points $P_{i}\left(x_{i}, y_{i}, z_{i}\right)$ $(i=1 \sim 8)$ around the point $P_{t}$ and their corresponding unit normal vectors $\vec{n}_{i}\left(n_{x i}, n_{y i}, n_{z i}\right)$ are selected to form the search region, and the objective function is established as in equation (2). The position of the point $P_{s}$ could be searched by iteratively calculating and comparing the value of the function $f$ of the point $P_{i}$.

$$
\min f\left(x_{s}, y_{s}, z_{s}\right)=\min \left(1-\cos \left\langle\vec{m}, \overrightarrow{n_{s}}\right\rangle\right) .
$$

This paper researches the single direction matching method with the example of tooth surface matched by moving along the $X$-axis and rotating around the $X$-axis.

\subsection{Matching Method for the Measured and Its Theoretical} Tooth Surface in Single Direction. The iterative search calculation diagram is shown in Figure 3. The point $P_{m}$ is taken as the origin of the coordinate system, the moving distance and rotating angle are taken as the $X$-axis and $Y$-axis, and the optimal matching point $P_{c}$ of the two surfaces is searched by the iteration method in this figure.

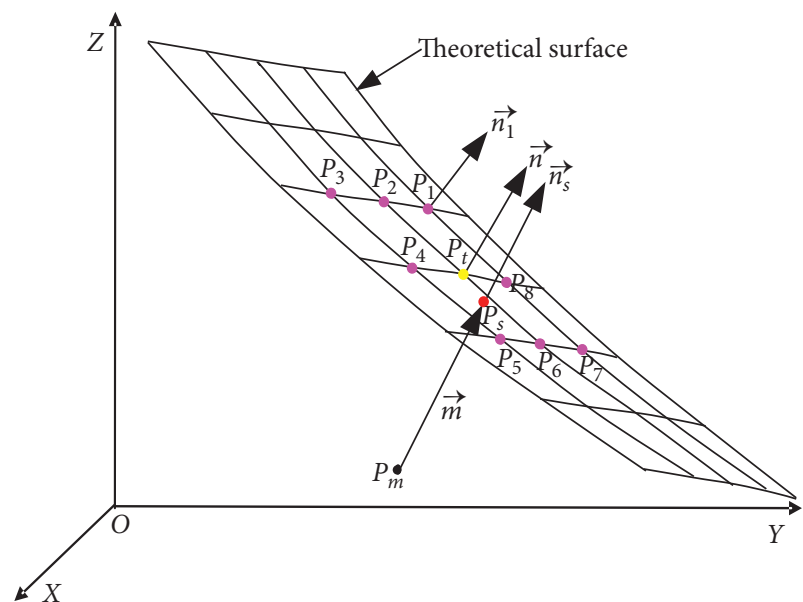

Figure 2: The search region for searching the point $P_{s}$.

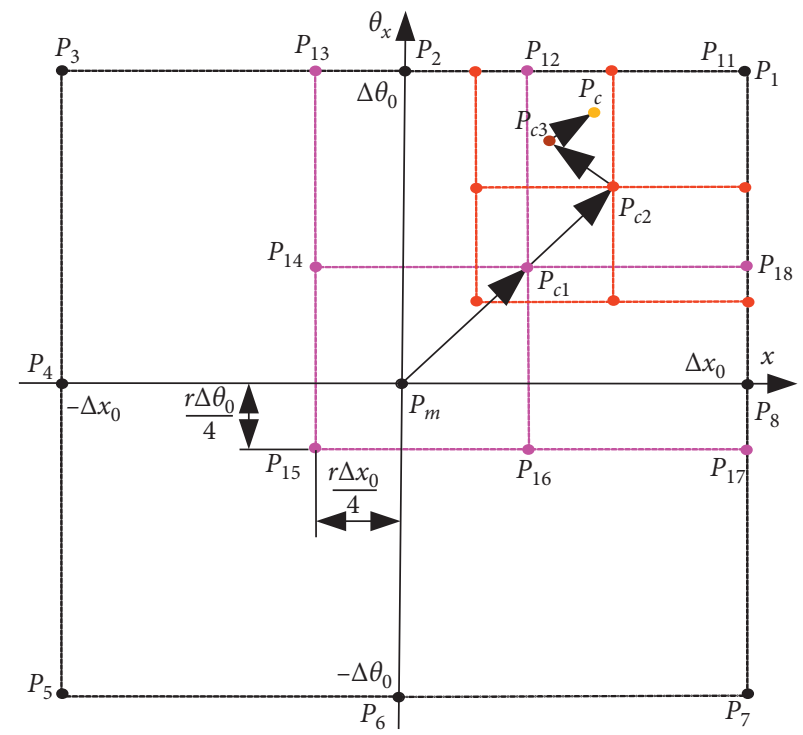

FIgURE 3: The iterative search calculation diagram.

First, set the initial search step $\Delta x_{0}$ and $\Delta \theta_{0}$ to ensure that the initial search region could enclose the point $P_{c}$. Set the matching parameters $\Delta x=0$, and $\Delta \theta_{x}=0$. The specific process is as follows:

(1) Move the point $P_{m}$ with a distance $\Delta x_{0}$ along with the positive and negative directions of the $X$-axis, a distance $\Delta \theta_{0}$ along with the positive and negative directions of the $\theta_{x}$ axis, respectively. Together with the point $P_{m}$, nine new matched points are obtained and named $P_{0} \sim P_{8}$. According to equation (1), the objective function value $F_{i}(i=0-8)$ could be calculated. Compare the value $F_{i}(i=0-8)$, and the new search region is judged according to the minimum value. For example, if $F_{1}$ is the minimum value, the new search region is the first quadrant shown in Figure 3.

(2) The new search direction is determined according to the new search region, and the step size is reduced to 
half of the original step, that is $\Delta x_{0} / 2^{k}$ and $\Delta \theta_{x 0} / 2^{k}$. If the point $P_{c}$ is in the first quadrant, the coefficients corresponding to the search direction are recorded as $\alpha_{1}=1$ and $\beta_{1}=1$. If the point $P_{c}$ is in the second quadrant, the coefficients is recorded as $\alpha_{1}=-1$ and $\beta_{1}=1$, and so on. In order to ensure that the optimization point is always in the search region, when a new search process is carried out, the search region is expanded with a distance of $r \Delta x_{0} / 2^{k+1}$ and $r \Delta \theta_{x 0} / 2^{k+1}$, where $r$ is the ratio. Generally, the value of $r$ is 0.5 . The new step size can be calculated by the following:

$$
\left\{\begin{array}{l}
\Delta x_{1}=\Delta x_{0} \cdot\left(2^{-k}+2^{-(k+1)} r\right), \\
\Delta \theta_{x 1}=\Delta \theta_{x 0} \cdot\left(2^{-k}+2^{-(k+1)} r\right) .
\end{array}\right.
$$

(3) Along the search direction, move the point $P_{m}$ with a distance $\Delta x_{1}^{\prime}$ and $\Delta \theta_{x 1}^{\prime}$ to get a new matched point $P_{c 1}$. The distance could be calculated by the following:

$$
\left\{\begin{array}{l}
\Delta x_{1}^{\prime}=\alpha_{1} \cdot \Delta x_{0} \cdot\left(2^{-k}-2^{-(k+1)} r\right), \\
\Delta \theta_{x 1}^{\prime}=\beta_{1} \cdot \Delta \theta_{x 0} \cdot\left(2^{-k}-2^{-(k+1)} r\right) .
\end{array}\right.
$$

Take the point $P_{c 1}$ as the center, and $\Delta x_{1}$ and $\Delta \theta_{x 1}$ as the step size, repeat steps (1) and (2) to get the new search region, the search direction coefficients $\alpha_{2}$ and $\beta_{2}$, the new step size $\Delta x_{2}$ and $\Delta \theta_{x 2}$, and the moving distance $\Delta x_{2}^{\prime}$ and $\Delta \theta_{x 2}^{\prime}$.

(4) After the $k$-th iteration, the moving distance of the matched point is calculated. Move the point according to the moving distance $\Delta x_{k}^{\prime}$ and $\Delta \theta_{x k}^{\prime}$ to get the new matched point $P_{c k}$, and then repeat step (1).

(5) After the $k$-th iteration, if the steps $\Delta x_{k}$ along the $X$ axis and $\Delta \theta_{x k}$ around the $X$-axis are less than $\varepsilon$, the iteration search results meet the accuracy requirements, and the iteration ended.

After the iteration, the matched results of the two tooth surfaces could be obtained, and the compensation value for the tooth surface measurement errors of the spiral bevel gear could be calculated by the following:

$$
\left\{\begin{array}{l}
\Delta x^{\prime}=\sum_{1}^{k} \alpha_{k} \cdot \Delta x_{0} \cdot\left(2^{-k}-2^{-(k+1)} r\right), \\
\Delta \theta_{x}^{\prime}=\sum_{1}^{k} \beta_{k} \cdot \Delta \theta_{x 0} \cdot\left(2^{-k}-2^{-(k+1)} r\right) .
\end{array}\right.
$$

The specific iteration process is shown in Figure 4.

\subsection{Matching Method for the Measured and Its Theoretical} Tooth Surface in Multiple Directions. In this iteration process, four parameters $\Delta x, \Delta y, \Delta \theta_{x}$ and $\Delta \theta_{y}$ should be calculated. In order to reduce the calculation work, the initial iteration (coarse matching) is carried out first, and then the

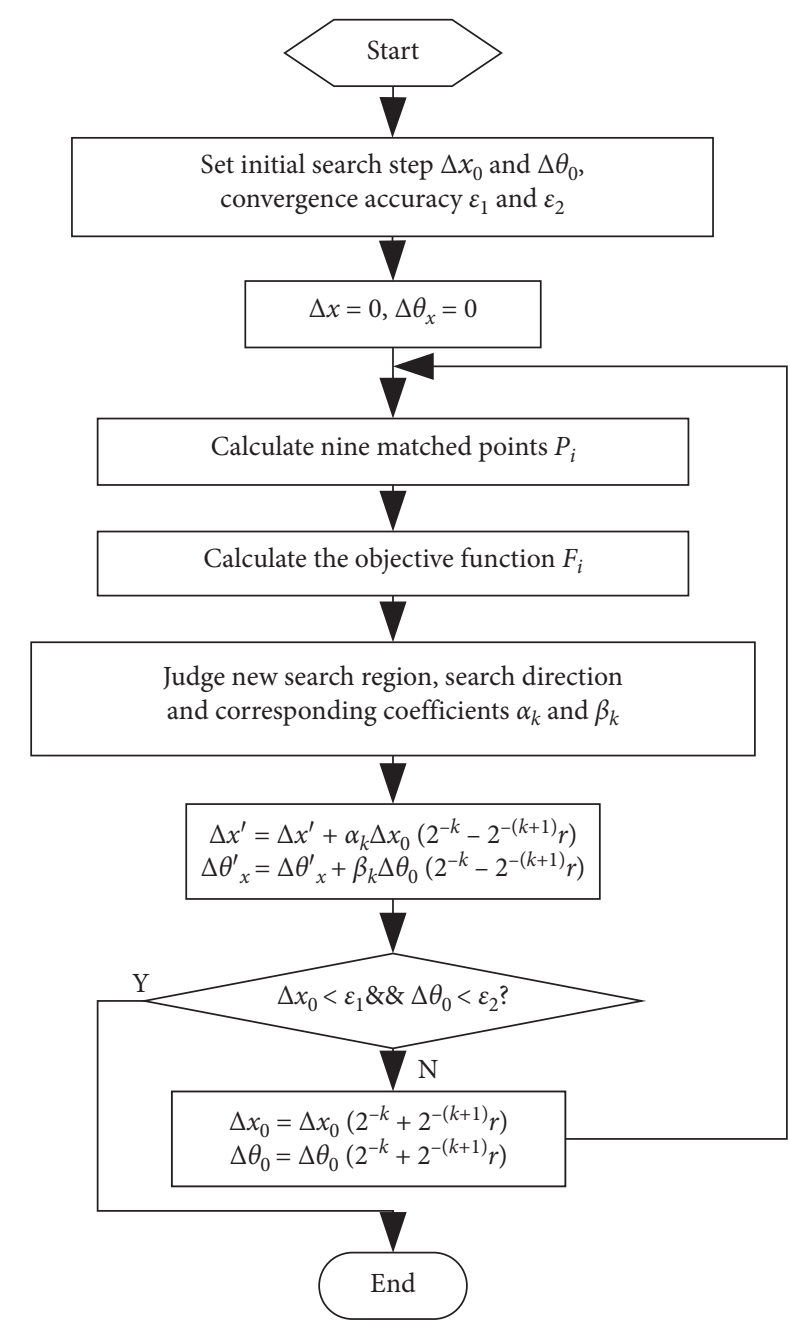

FIgURE 4: Flow chart of the iteration process.

accurate iteration (precision matching) in two directions is carried out. The specific process is shown in Figure 5.

The coarse matching process is as follows: According to the matching method for a single direction, match the tooth surface along and around $X$-axis for $n$ times and then match the tooth surface along and around $Y$-axis for $n$ times. Judge whether the tooth surface deviation is less than the end criterion of the iteration. If the deviation is less than the criterion, skip the cycle and turn it into the accurate iteration process; otherwise, continue the iteration.

The accurate iteration process is as follows: first, match the tooth surface along and around $X$-axis for 1 time according to the matching method for a single direction, and then match the surface along and around $Y$-axis for 1 time. Judge whether the deviation meets the end criterion of the iteration. If it does not meet the criterion, return and continue the iteration until the criterion is met, and then calculate the matching results of the tooth surface according to the matching method.

Finally, the compensation value of the tooth surface measurement errors of the spiral bevel gear in two directions could be calculated by equation (5). 


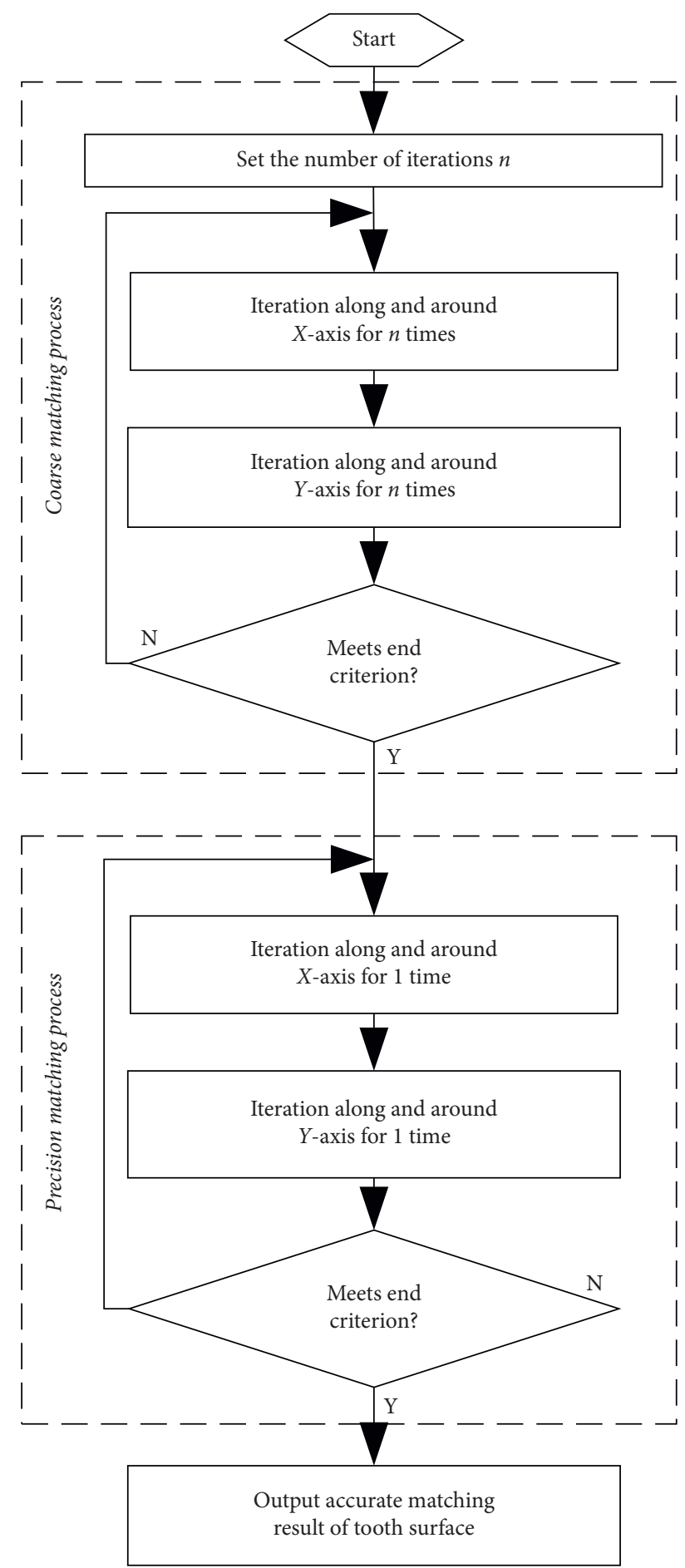

FIGURE 5: Flow chart of a precision matching method for multiple directions.

\section{Experiment Results and Analysis of the Compensation Method}

4.1. Basic Data of the Measured Gear. The parameters of the measured spiral bevel gear are shown in Table 1.

The theoretical points of the tooth surface are selected along three profile lines named PL7, PL15, and PL23, and one tooth trace line named TL5, as shown in Figure 6. Each
TABLE 1: The parameters of the measured spiral bevel gear.

\begin{tabular}{lc}
\hline Type & Gear \\
\hline No. of teeth & 56 \\
Pitch diameter $(\mathrm{mm})$ & 72.800 \\
Pressure angle $\left({ }^{\circ}\right)$ & 20.000 \\
Shaft angle $\left(^{\circ}\right)$ & 90.000 \\
Pitch angle $\left({ }^{\circ}\right)$ & 75.967 \\
Face angle $\left(^{\circ}\right)$ & 76.567 \\
Root angle $\left(^{\circ}\right)$ & 73.867 \\
Mounting distance $(\mathrm{mm})$ & 22.350 \\
\hline
\end{tabular}

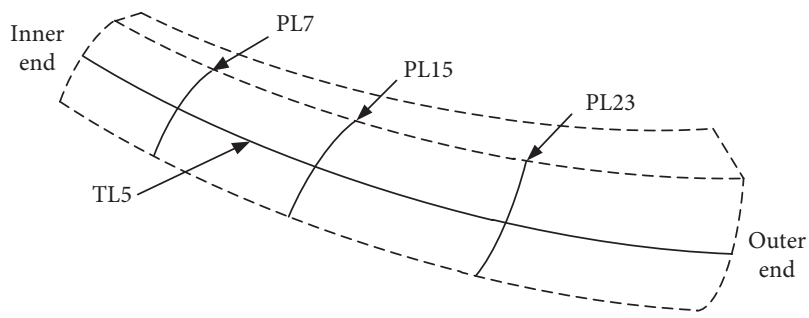

FIgURE 6: The theoretical points of the tooth surface of the spiral bevel gear.

line has 113 theoretical points. The theoretical data both for the convex and the concave surfaces contain the coordinates and unit normal vectors of these theoretical points. According to these theoretical data, actual measurement experiments are done and the measured tooth surface are the convex and concave surfaces of Tooth 1, Tooth 15, Tooth 29, and Tooth 43 of the gear. In the actual measurement experiment, some assembly errors are added artificially.

According to the compensation method proposed in the paper, the point cloud of the measured tooth surface could be matched with the theoretical tooth surface, and the compensation values could also be calculated by equation (5). Compared with the errors of the measured value, the accuracy of the compensation could be calculated.

4.2. The Compensation Results and Analysis. Figure 7 shows the comparisons of the measurement errors of the measured points along the tooth trace line both on the concave and convex tooth surface of Tooth 1 of the gear before and after compensation. Figures $7(\mathrm{a})$ and 7 (b) are the compensation results of the convex tooth surface in the $X$ direction and $Y$ direction, respectively, and Figures $7(\mathrm{c})$ and $7(\mathrm{~d})$ are the compensation results of the concave tooth surface in the $X$ direction and $Y$ direction, respectively.

After matching and compensation between the measured tooth surface and the theoretical tooth surface, the average measurement errors of the tooth surface along the $X$-axis and $Y$-axis of all measured tooth surfaces are shown in Tables 2 and 3, and the corresponding figures of the average errors of four teeth of the gear along the $X$-axis and $Y$-axis before and after compensation are shown in Figures 8 and 9 , respectively.

From Tables 2 and 3, Figures 8 and 9, it can be easily seen that, before the compensation process, the average errors of 


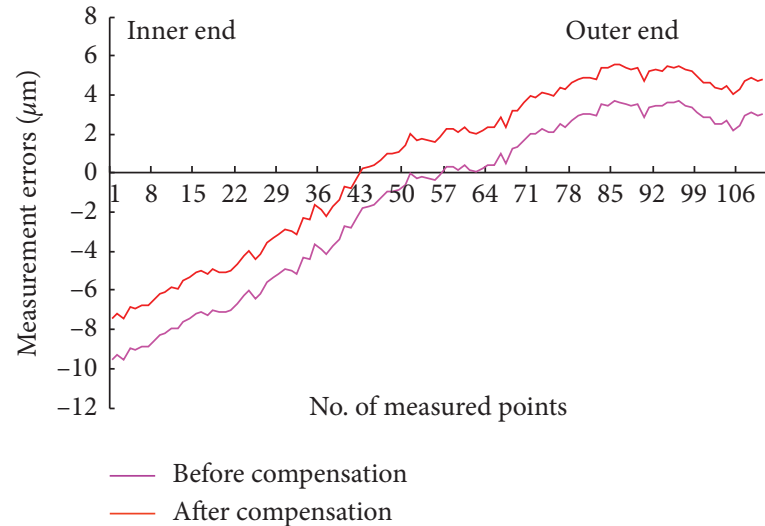

(a)

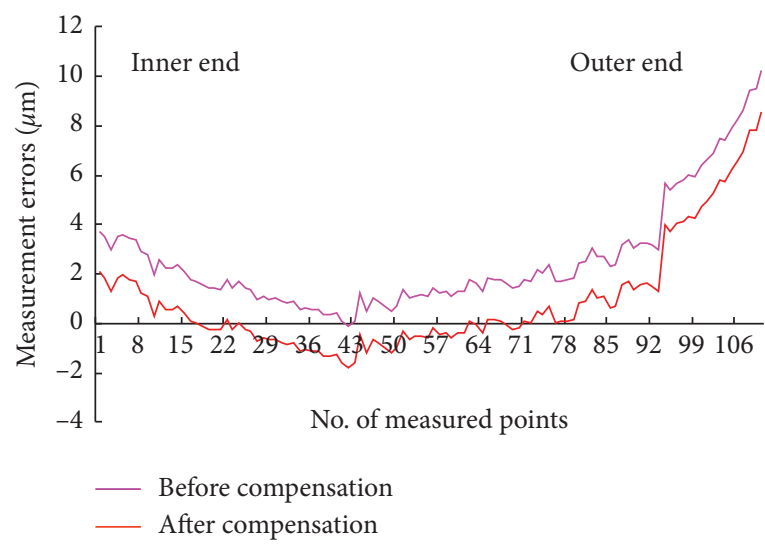

(c)

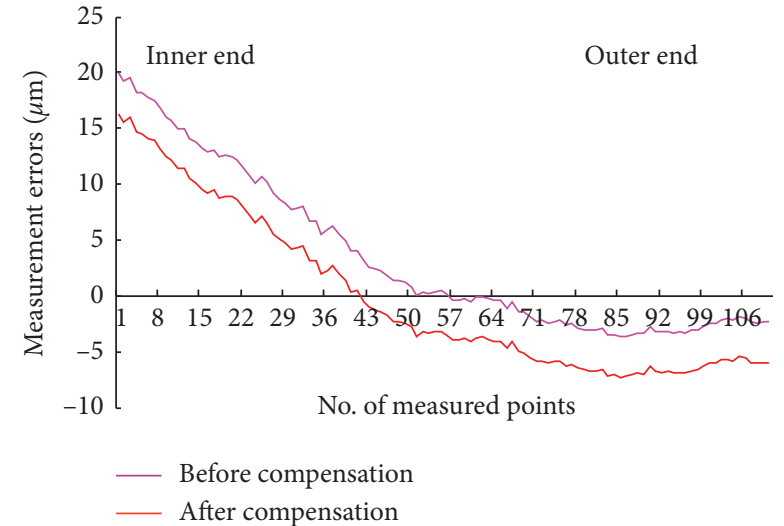

(b)

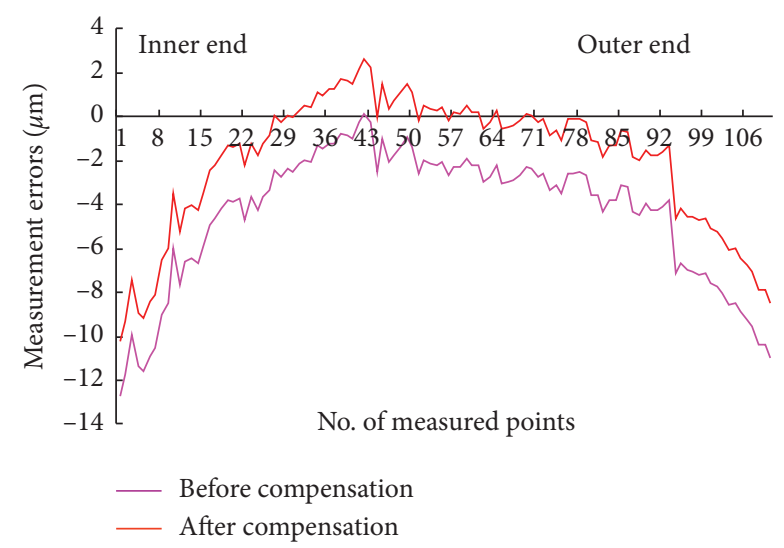

(d)

Figure 7: Comparisons of the measurement errors of the tooth trace line of tooth 1. (a) The convex flank along $X$ direction. (b) The convex flank along $Y$ direction. (c) The concave flank along $X$ direction. (d) The concave flank along $Y$ direction.

TABLE 2: Average errors of four tooth flanks before and after compensation ( $X$ direction).

\begin{tabular}{lccccc}
\hline No. of tooth surface & & $\begin{array}{c}\text { Errors before } \\
\text { compensation } \\
(\mu \mathrm{m})\end{array}$ & $\begin{array}{c}\text { Compensation } \\
\text { value }(\mu \mathrm{m})\end{array}$ & $\begin{array}{c}\text { Errors after } \\
\text { compensation }(\mu \mathrm{m})\end{array}$ & $\begin{array}{c}\text { Compensation } \\
\text { effects }(\%)\end{array}$ \\
\hline \multirow{5}{*}{ Convex surface } & Tooth 1 & -1.73 & 1.85 & 0.12 & 0.001 \\
& Tooth 15 & -0.011 & 0.012 & 0.45 & 0.33 \\
& Tooth 29 & -2.03 & 2.48 & 0.05 & 77.8 \\
Concave & Tooth 43 & -1.65 & 1.98 & -0.47 & 79.6 \\
surface & Tooth 1 & 1.72 & -1.67 & 0.20 & 87.1 \\
& Tooth 15 & 3.15 & -1.14 & -0.15 & 85.1 \\
\hline
\end{tabular}


TABle 3: Average errors of four tooth flanks before and after compensation ( $Y$ direction).

\begin{tabular}{lccccc}
\hline \multirow{2}{*}{ No. of tooth surface } & Errors before & $\begin{array}{c}\text { Compensation } \\
\text { value }(\mu \mathrm{m})\end{array}$ & $\begin{array}{c}\text { Errors after } \\
\text { compensation }(\mu \mathrm{m})\end{array}$ & $\begin{array}{c}\text { Compensation } \\
\text { effects }(\%)\end{array}$ \\
\hline \multirow{3}{*}{ Convex } & Tooth 1 & 3.27 & -3.61 & -0.34 & 0.48 \\
surface & Tooth 15 & 1.68 & -1.20 & 0.06 & 71.3 \\
& Tooth 29 & 3.46 & -3.40 & 0.23 & 98.4 \\
\hline \multirow{3}{*}{ Concave } & Tooth 43 & 2.64 & -2.41 & -0.18 & 91.4 \\
surface & Tooth 1 & -2.85 & 2.67 & -0.37 & 93.5 \\
& Tooth 15 & -4.38 & 4.01 & -0.24 & 87.5 \\
\hline
\end{tabular}

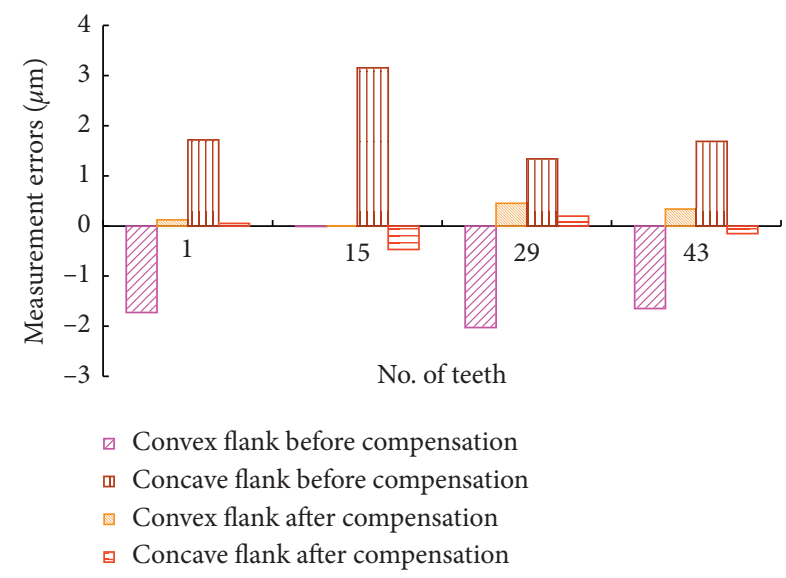

Figure 8: Average errors of all tooth flanks before and after compensation ( $X$ direction).

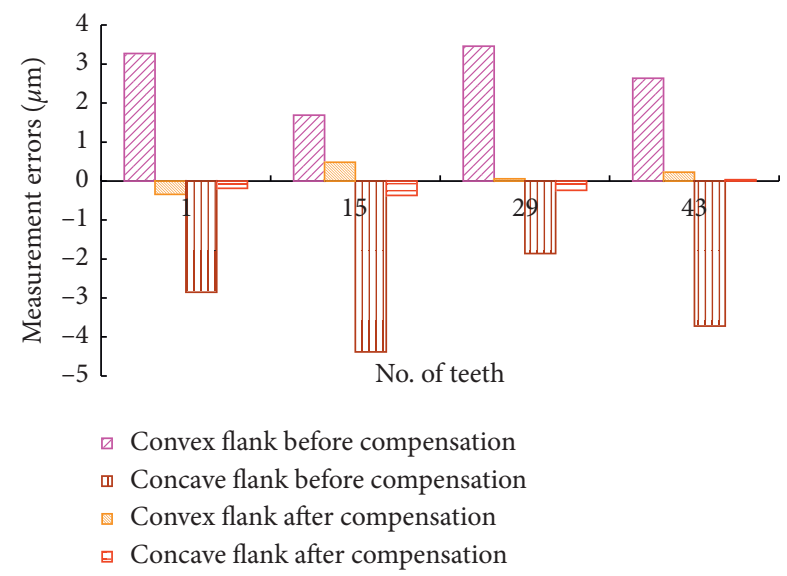

Figure 9: Average errors of all tooth flanks before and after compensation ( $Y$ direction).

some tooth flank are more than $3 \mu \mathrm{m}$. After matching and the compensation process, the average errors of the measurement results of all tooth surfaces are less than $0.5 \mu \mathrm{m}$, and more than $70 \%$ of the measurement errors are compensated by the proposed method.

\section{Conclusions}

In order to improve the accuracy of the measurement results of the spiral bevel gear tooth surface, this paper presents a precision compensation method for the inclination error of the gear tooth surface. Based on the iterative search method, this paper established an objective function to match the theoretical tooth surface and actual tooth surface along and around $X$-axis and $Y$-axis accurately and then compensated the measurement errors of the tooth surface according to the matching method.

The experimental results show that the errors included in the tooth surface measurement results along and around the $X$-axis, $Y$-axis are reduced from more than $3 \mu \mathrm{m}$ to less than $0.5 \mu \mathrm{m}$, and more than $70 \%$ of the errors are compensated by the proposed compensation method. The results show that the measurement errors in the above directions can be eliminated obviously, and this method can provide a more accurate basis for the adjustment of machine tool parameters in the manufacturing process.

\section{Data Availability}

The processed data cannot be shared at this time as the data also form part of an ongoing study.

\section{Conflicts of Interest}

The authors declare that there are no conflicts of interest regarding the publication of this paper.

\section{Acknowledgments}

This work was supported in part by the Natural Science Foundation of Shaanxi Province (2019JQ-556), in part by the Open Research Project of Key Laboratory of Advanced Manufacture Technology for Automobile Parts (Chongqing University of Technology), MOE (2017KLMT06), in part by the Major Science and Technology Projects of Shaanxi Province (2018zdzx01-01-01), and in part by the Fundamental Research Funds for the Central Universities, CHD (300102250111). 


\section{References}

[1] V. Vullo, "Spiral bevel gears and hypoid gears," in Gears. Springer Series in Solid and Structural Mechanics, vol. 10, pp. 569-694, Springer, Berlin, Germany, 2020.

[2] V. V. Simon, "Multi-objective optimization of hypoid gears to improve operating characteristics," Mechanism and Machine Theory, vol. 146, Article ID 103727, 2020.

[3] F. Samani, M. Molaie, and F. Pellicano, "Nonlinear vibration of the spiral bevel gear with a novel tooth surface modification method," Meccanica, vol. 54, no. 7, pp. 1071-1081, 2019.

[4] R. Takeda, M. Komori, T. Nishino et al., "Performance analysis of generated hypoid gear based on measured tooth flank form data," Mechanism and Machine Theory, vol. 72, pp. 1-16, 2014.

[5] G. Goch, "Gear metrology," CIRP Annals, vol. 52, no. 2, pp. 659-695, 2003.

[6] R. Khusainov, V. Stupko, and Y. Yu, "Automated measurement of bevel gears," in Proceedings of the International Multi- Conference on Industrial Engineering and Modern Technologies, p. 6, Vladivostok, Russia, October 2019.

[7] P. Yin, J. Wang, and C. Lu, "Measuring software test verification for complex workpieces based on virtual gear measuring instrument," Measurement Science Review, vol. 17, no. 7, pp. 197-207, 2017.

[8] S. Fang, Y. Liu, H. Wang, T. Taguchi, and R. Takeda, "Compensation method for the alignment angle error of a gear axis in profile deviation measurement," Measurement Science and Technology, vol. 24, no. 5, Article ID 055008, 2013.

[9] Y. Liu, S. Fang, H. Wang, T. Taguchi, and R. Takeda, "Compensation method for the alignment angle error in pitch deviation measurement," Measurement Science and Technology, vol. 27, no. 5, Article ID 055006, 2016.

[10] R. Takeda, S. Fang, Y. Liu, and M. Komori, "Precision compensation method for tooth flank measurement error of hypoid gear," Measurement, vol. 89, pp. 305-311, 2016.

[11] A. Fuentes, R. Ruiz-Orzaez, and I. Gonzalez-Perez, "Compensation of errors of alignment caused by shaft deflections in spiral bevel gear drives," in Theory and Practice of Gearing and Transmissions, vol. 34, pp. 301-319, Springer, Berlin, Germany, 2016.

[12] I. Gonzalez-Perez and A. Fuentes-Aznar, "Tooth contact analysis of cylindrical gears reconstructed from point clouds," in New Approaches to Gear Design and Production, vol. 81, pp. 219-237, Springer, Berlin, Germany, 2020.

[13] H. Guo and A. Fuentes-Aznar, "Compensation of errors of alignment caused by shaft deflections in face-gear drives generated by shaper cutters," Mechanism and Machine Theory, vol. 144, Article ID 103667, 2020.

[14] H. Ding, J. Tang, and W. Shao, "Automatic data-driven operation and optimization of uncertain misalignment by considering mechanical power transmission performances of spiral bevel and hypoid gears," Applied Soft Computing, vol. 82, Article ID 105600, 2019.

[15] W. Shao, H. Ding, and J. Tang, "Data-driven operation and compensation approaches to tooth flank form error measurement for spiral bevel and hypoid gears," Measurement, vol. 122, pp. 347-357, 2018.

[16] X. Fu, G. Zhang, Y. Zhang, Y. Li, L. Jia, and Y. Guan, "A novel flatness detection method for spiral bevel gears in an automobile gearbox," Laser in Engineering, vol. 45, no. 1-3, pp. 189-200, 2020.

[17] Y.-P. Shih and C. H. You, "On-machine quasi-3D scanning measurement of bevel gears on a five-axis CNC machine,"
Journal of the Chinese Institute of Engineers, vol. 40, no. 3, pp. 207-218, 2017.

[18] G. Li, Z. H. Wang, and A. Kubo, "Error-sensitivity analysis for hypoid gears using a real tooth surface contact model," Proceedings of the Institution of Mechanical Engineers Part C-Journal of Mechanical Engineering Science, vol. 231, no. 3, pp. 507-521, 2015.

[19] Z. H. Wang, X. Zhou, T. Oguma, and A. Kubo, "Quality control of hypoid gears using gear measuring machine," in Proceedings of the International Technology and Innovation Conference, Hangzhou, China, November 2006.

[20] Z. Y. Wang, H. M. Zhai, and H. Chen, "On-machine measurement of tooth profile errors of spiral bevel gears and its simulation," Applied Mechanics and Materials, vol. 394, pp. 245-250, 2013.

[21] Y. Zhang, H. Yan, Z. Y. Wang, and Q. Zhao, "Tooth surface error correction methodologies for spiral bevel and hypoid gears generated by duplex helical method," in Proceedings of the International Conference on Advances in Construction Machinery and Vehicle Engineering, Changsha, China, May 2019.

[22] V. Simon, "Influence of tooth errors and misalignments on tooth contact in spiral bevel gears," Mechanism and Machine Theory, vol. 43, no. 10, pp. 1253-1267, 2008.

[23] M. S. Shunmugam, B. S. Rao, and V. Jayaprakash, "Establishing gear tooth surface geometry and normal deviationPart II-bevel gears," Mechanism and Machine Theory, vol. 33, no. 5, pp. 525-534, 1998.

[24] T. Peng, T. Lim, and J. Yang, "Eccentricity effect analysis in right-angle gear dynamics," in Proceedings of the International Design Engineering Technical Conferences, Washington, DC, USA, August 2011.

[25] S. Chen and H. Yan, "Research on tooth surface deviation correction algorithm of spiral bevel gear based on tilting method," China Mechanical Engineering, vol. 22, no. 9, pp. 1080-1084, 2011.

[26] X. Xie, X. Zhang, J. Jia, and G. Bo, "Coordinate measuring of the variable ratio noncircular bevel gear," in Proceedings of International Conference on Electronic \& Mechanical Engineering and Information Technology, Harbin, China, August 2011.

[27] X. Cao and X. Deng, "Deviation and correction of tooth surface for spiral bevel gears," in Proceedings of the International Conference on Mechanic Automation and Control Engineering, Wuhan, China, June 2010.

[28] Z.-y. Zhou, J.-y. Tang, and H. Ding, "Accurate modification methodology of universal machine tool settings for spiral bevel and hypoid gears," Proceedings of the Institution of Mechanical Engineers, Part B: Journal of Engineering Manufacture, vol. 232, no. 2, pp. 339-349, 2018.

[29] M. Shuai and Z. Yidu, "Spiral bevel gear true tooth surface precise modeling and experiments studies based on machining adjustment parameters," Proceedings of the Institution of Mechanical Engineers, Part C: Journal of Mechanical Engineering Science, vol. 229, no. 14, pp. 2524-2533, 2015. 